\title{
A Análise de Discurso, pecheutiana, na Teoria (De)colonial: por perspectivas, metodológicas, latino-americanas
}

\author{
Clándia Maria Serino Lacerda Muniz' \\ Luciana Vedovato ${ }^{2}$
}

\begin{abstract}
Resumo: um dos grandes êxitos da Análise de Discurso (AD), de Michel Pêcheux, parece ter sido a construção de um dispositivo, metodológico, capaz de transpassar a superficialidade da língua, buscando a produção de sentidos, nela materializados, por sujeitos interpelados pela história e ideologia. Assim, busca-se, com este ensaio, refletir sobre as possíveis contribuições desta abordagem, aqui denominada $\mathrm{AD}$, para os estudos discursivos desde (e para) a América Latina, a partir da ressignificação de alguns conceitos, na interface com a Teoria (De)colonial. A pesquisa se ampara nos indícios de que as Ciências Sociais vivem uma crise de paradigma, não dando mais conta de responder as problemáticas, geo-historicamente construídas, que afetam o mundo, especialmente os países do Sul, tornando-se necessário pensar epistemologias outras. Assim, tem-se como questões norteadoras: como pensar a AD desde (e para) o Sul? Quais os limites e as possibilidades de diálogo entre a AD, pecheutiana, e a Teoria (De)colonial? As análises se orientam por abordagem interdisciplinar, nas sendas da pesquisa qualitativa, combinando reflexão teórica, historiográfica e uma estratégia temporal que não é linear. Os resultados revelam que é possível uma aproximação entre ambas as perspectivas, desde que se reconheça o "lugar de fala" de cada teórico e se estabeleça um diálogo, horizontal, entre as teorias do Sul e do Norte.
\end{abstract}

Palavras-chave: Análise de Discurso; Metodologia; Giro Decolonial; América Latina.

\section{Pecheutian Discourse Analysis in Decolonial Theory: For latin american methodological perspectives}

\footnotetext{
Doutoranda do Programa de Pós-graduação Interdisciplinar em Sociedade, Cultura e Fronteiras, da Universidade Estadual do Oeste do Paraná (Unioeste), Campus de Foz do Iguaçu, PR, Brasil. Secretária Executiva da Universidade Federal da Integração Latino-americana. E-mail: claudialacerda84@gmail.com

2 Doutora pela Universidade do Rio Grande do Sul, no Programa de Pós-graduação em Letras - Estudos do Texto e do Discurso - e professora efetiva do colegiado de Letras, na área de Linguística, e do Programa de Pós-graduação em Sociedade, Cultura e Fronteiras, da Universidade Estadual do Oeste do Paraná - Unioeste/ Foz do Iguaçu. E-mail: lucianavedovato@yahoo.com.br
} 


\begin{abstract}
Discourse Analysis (AD), by Michel Pêcheux, seems to have been the construction of a methodological device, capable of crossing the superficiality of language, seeking the production of meanings, materialized in it, by subjects challenged by history and ideology. Thus, this essay seeks to reflect on the possible contributions of this approach, here called AD, to discursive studies since (and for) Latin America, based on the reframing of some concepts, at the interface with Theory ( De) colonial. The research is supported by the evidence that the Social Sciences are experiencing a paradigm crisis, no longer being able to answer the problems, geo-historically constructed, that affect the world, especially the countries of the South, making it necessary to think about other epistemologies. Thus, the guiding questions are: how to think of DA from (and to) the South? What are the limits and possibilities of dialogue between AD, Pecheutian, and colonial (De) Theory? The analyzes are guided by an interdisciplinary approach, on the paths of qualitative research, combining theoretical, historiographical reflection and a temporal strategy that is not linear. The results reveal that an approximation between both perspectives is possible, as long as the "place of speech" of each theorist is recognized and a horizontal dialogue is established between the theories of the South and the North.
\end{abstract}

Keywords: Discourse Analysis; Methodology; Decolonial Turn; Latin America. 


\section{Introdução}

Um dos grandes feitos da Análise de Discurso (AD), pecheutiana, parece ter sido a construção de um aparato teórico-analítico capaz de perfurar a exterioridade da língua, conforme expressa Frederico Carvalho $(2008)^{3}$, chegando ao nível da construção de sentidos por sujeitos atravessados tanto pelo inconsciente quanto pela história e ideologia.

Assim, a AD, pecheutiana, como perspectiva teórico-metodológica, pode contribuir, proficuamente, para a compreensão dos processos de produção e reprodução da ordem mundial, bem como das relações de dominação, exploração e classificação social dos sujeitos.

Considerando os objetivos da Teoria (De)colonial que realiza sólidas críticas às narrativas eurocêntricas, como padrão civilizatório universal, visando romper com a história única e a naturalização da inferioridade das antigas colônias, busca-se, aqui, refletir sobre as possíveis contribuições (e limites) da AD, de Michel Pêcheux (2008; 2014á; 2014b), para se pensar os estudos críticos, do discurso, desde (e para) o Sul.

Antes, contudo, faz-se necessário esclarecer que a Teoria (De)colonial não é a única a proferir críticas às epistemologias eurocêntricas. Há uma série de pesquisas que contribuem, distintamente, com orientações nas diversas áreas de conhecimento: ciências sociais, história, crítica literária, estudos culturais, estudos pós-coloniais, política, filosofia etc. O que essas perspectivas têm em comum é o fato de proporem uma releitura da história, tendo a colonização como parte de um processo universal.

Tais estudos apontam para novas alternativas epistemológicas e de análise sociocultural, visando à reformulação da geopolítica do conhecimento, onde todos possam coexistir e pensar. Algumas das principais pesquisas, nesse campo, foram, inicialmente, desenvolvidas por imigrantes, segundo Luiz Antonio Guerra (2014), nos departamentos de crítica literária, de universidades europeias, e denominadas estudos pós-coloniais. A intenção parece ter sido buscar alternativas à superação do colonialismo europeu, em suas leituras sobre os continentes latino-americano, africano e asiático.

$\mathrm{Na}$ América Latina, o pós-colonialismo ganhou visibilidade no final da década de 1980 e foi denominado, pelos seus precursores, de "pensamento decolonial". Nesse processo de empreender crítica ao paradigma moderno, com base na perspectiva histórica da colonialidade latino-americana, destacam-se teóricos, como: Aníbal Quijano, Walter Mignolo, Edgardo Lander, dentre outros.

Para identificar aproximações e distanciamentos entre a AD, na vertente pecheutiana, e o giro decolonial, este ensaio se orienta por uma abordagem interdisciplinar, nas sendas da pesquisa qualitativa, recorrendo, sucintamente, à constituição histórica e aos conceitos basilares de ambas as perspectivas.

3 Por opção metodológica, os autores, referenciados neste ensaio, terão seus nomes integralmente registrados quando citados pela primeira vez. 
Por questões metodológicas, e visando organizar a reflexão empreendida, o texto foi estruturado em três sessões: a primeira aborda os princípios teórico-metodológicos da $\mathrm{AD}$, propostos por Michel Pêcheux; a segunda apresenta a constituição histórica e a natureza dos estudos (de)coloniais; a terceira realiza um comparativo entre as duas perspectivas, apresentando os limites de diálogo e os desafios para se pensar a AD desde (e para) o Sul.

\section{A Análise de Discurso pecheutiana: constituição histórica e teórico-metodológica}

Michel Pêcheux é considerado um dos principais teóricos dos estudos discursivos europeus, especialmente na França, junto ao filósofo Michel Foucault. Talvez seja por isso que se convencionou designar esta abordagem de AD Francesa. Contudo, foi pouco lido, quando vivo, segundo Emanuelle de Souza Barbosa (2016), velando-se sob o nome de Thomas Hebert.

No início de sua carreira científica, dedicou-se a um árduo trabalho, interdisciplinar, de questionamento e deslocamento de três áreas do saber linguística, materialismo histórico e psicanálise a partir das quais se propôs a pensar a produção de sentidos que ocorre entre o sujeito, a língua e a história, revelando as ideologias presentes no interior de cada discurso (Figura 1).

Figura 1: dispositivo teórico-analítico proposto por Michel Pêcheux

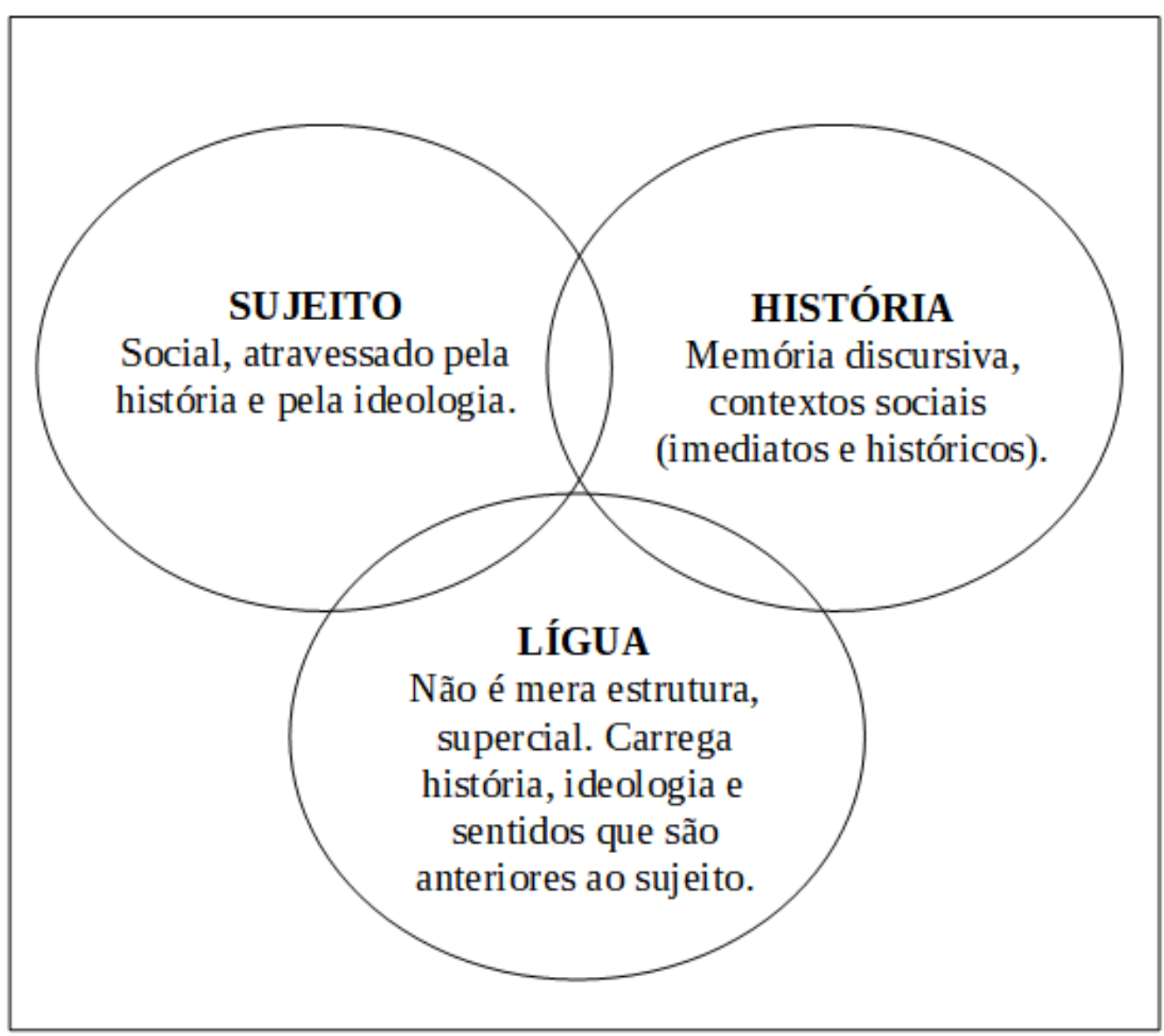

Fonte: elaborado pelas autoras. 
A AD, proposta por Pêcheux, na década de 1969, possuía caráter intervencionista. Era politicamente engajada e oferecia novas alternativas para pensar as Ciências Sociais visando à superação do positivismo, no cenário francês. Influenciado por Louis Althusser, ocupou um espaço importante, no meio científico, ao se propor a pensar o sujeito, ideológico, dentro de seu campo de estudo a materialidade específica da língua (MALDIDIER, 2003).

Assim, Pêcheux traçou um caminho, no terreno epistemológico, para fundar uma ciência, com método próprio, transpassada pela teoria da ideologia, o materialismo histórico, a psicanálise (por meio da releitura lacaniana do legado de Sigmund Freud) e a linguística, com base na revisão da obra de Ferdinand de Saussure.

Os conceitos tomados de empréstimo, dessas áreas de conhecimento contribuíram para que Pêcheux pudesse (re) pensar as noções de língua, história e sujeito, dentro de seu objeto de estudo - o discurso - sem sucumbir à influência daquelas.

Dessa forma, foi possível fragilizar o formalismo existente no meio científico da época, afrontando concepções automáticas, a respeito da língua, que não reconheciam as contradições presentes na história e no indivíduo, assujeitado (interpelado pela ideologia) e marcado por falhas impressas em seu inconsciente.

O sistema discursivo pecheutiano configura-se, portanto, como um corpo transpassado por equívocos, onde a língua aparece como lugar de falhas, o sujeito como inquirido pelo inconsciente e pela ideologia e a história como contraditória e não linear.

É nesse ponto que parece haver convergência da AD, de Pêcheux, com a Teoria (De) colonial, podendo atuarem conjuntamente, enquanto perspectivas metodológica e teórica, na compreensão dos processos de produção e reprodução da ordem mundial. Isso porque as categorias "sujeito", "história" e "ideologia" são, igualmente, relevantes para as discussões empreendidas, por ambas as abordagens, em torno da ideia de exploração e classificação social dos sujeitos, embora utilizem distintas categorias, centrais, de análise - "classe" e "raça", respectivamente - como se pode observar na seção seguinte.

\section{Estudos (de)coloniais: constituição histórica e conceitos basilares}

A perspectiva (De)colonial é um espaço enunciativo, não isento de contradições, que tem a "colonialidade", em suas diferentes formas, como principal categoria de problematização. Surgiu com diferentes intelectuais latino-americanos (e outros teóricos, não latinos, cujo lugar de episteme é a América Latina), situados em distintas universidades das Américas.

O movimento epistemológico do coletivo foi fundamental à renovação das Ciências Sociais, na América Latina, no século XXI, atualizando a tradição crítica do pensamento latino-americano. Defende a opção "decolonial” - política, epistêmica e teórica - para a compreensão sistêmica do mundo, privilegiando os saberes e conhecimentos dos grupos, historicamente, silenciados. 
Para o sociólogo peruano, Aníbal Quijano (2009), o conceito de colonialidade diz respeito às condições de assentamento do sistema capitalista - como padrão de funcionamento das relações de poder na modernidade - que operam por meio da "imposição de uma classificação racial-étnica da população do mundo" (QUIJANO, 2009, p. 105-106). Esta lógica subsidia um novo paradigma de império, a "colonialidade do poder", que classifica, socialmente, os sujeitos, com base na ideia de "raça".

Este conceito (raça), de acordo com o autor, serviu de justificativa para a dominação e exploração colonial. Com base nele, e a partir das demandas do capital, o colonizador europeu nominou a América, que não existia antes de o homem branco, europeu, invadi-la, no ano de 1492, marco das teorizações (de)coloniais:

Dos procesos históricos convergieron y se asociaron en la producción de dicho espacio/ tempo y se establecieron como los dos ejes fundamentales del nuevo patrón de poder. De una parte, la codificación de las diferencias entre conquistadores y conquistados en la idea de raza, es decir, una supuesta diferente estructura biológica que ubicaba a los unos en situación natural de inferioridade respecto de los otros. [...] De otra parte, la articulación de todas las formas históricas de control del trabajo, de sus recursos y de sus productos, en torno del capital y del mercado mundial (QUIJANO, 2014, p. 778)..

Assim, como pontua Quijano (2014), a racialização foi o primeiro processo histórico por meio do qual a Europa construiu uma narrativa, hierarquizante, entre a população mundial, forjando supostas diferenças biológicas entre dominantes/colonizadores e dominados/ colonizados. Aos últimos (negros e índios, conforme designações atribuídas pelo homem branco), foi conferida uma inferioridade natural, que os condicionou à servidão, capitalista, imposta pelo homem europeu.

O segundo aspecto que contribuiu para o estabelecimento da "colonialidade do poder", segundo o autor, refere-se à racionalização do trabalho, que combinou todas as formas, históricas, de controle laboral, em torno do capital, para atender ao mercado global: escravidão, regime de servidão, regime salarial, pequenas produções mercantis.

Dessa forma, o sistema de dominação social, tipificado na ideia de "raça", instituiu a divisão do trabalho, organizando-o conforme a hierarquia racial: o trabalho árduo, de menor reconhecimento, foi atribuído aos não europeus e o trabalho assalariado, de maior prestígio, facultado àqueles considerados, racialmente, superiores.

Essa hierarquia - sustentada pela "colonialidade do poder" - se naturalizou e permanece, até os dias atuais, estruturada nas interfaces com a "colonialidade do saber" e a "colonialidade do ser", dividindo o mundo entre "países desenvolvidos e em desenvolvimento".

A “colonialidade do saber” revela, como lembra Carlos Walter Porto-Gonçalves (2005), que, para além do legado de injustiça e desigualdade sociais, oriundos do imperialismo europeu, há uma herança, epistemológica, do eurocentrismo que impede os países, do hemisfério Sul, de compreender o mundo com base nas próprias experiências, considerando as epistemes que lhes são próprias. Reproduz-se, então, uma epistemologia eurocêntrica, branca, cristã e patriarcal que se autoconcede a exclusividade na construção e universalização de conhecimentos legítimos. 
Essa face da colonialidade cria uma identidade estigmatizada para os povos inferiorizados - a "colonialidade do ser". O termo, sugerido pelo teórico (de)colonial Walter Mignolo, baseia-se na internalização da subalternidade e negação do "Outro", afetado pela dominação colonial, por meio da naturalização do eurocentrismo e do silenciamento dos modos de existência desses sujeitos.

Nessa direção, os Estudos (De)coloniais buscam desconstruir a narrativa europeia, segundo a qual o saber nasce com o homem europeu, considerado o único capaz de alcançar a universalidade, relegando os demais saberes, fora dos padrões eurocêntricos, à condição de primitividade, particularidade e folclorização.

Para tanto, faz-se necessário romper com os pensamentos, coloniais, gravados na mente dos sujeitos subalternizados, inaugurados com o início do colonialismo, na América Latina, e naturalizados com a constituição colonial dos saberes, da memória, das linguagens, do imaginário (MIGNOLO, 2005).

É nesse ponto que a AD, pecheutiana, enquanto abordagem teórico-metodológica, pode contribuir, dentro das limitações que lhe são próprias, para a (de)colonização do pensamento latino-americano, possibilitando pensar os estudos do discurso desde (e para) o Sul.

\section{Aproximações e distanciamentos entre a Análise de Discurso, pecheutiana, e a Teoria (De)colonial: o "lugar de fala"}

As similitudes entre a AD, pecheutiana, e os Estudos Decolonais começam pelo objetivo de ambas as perspectivas: engendrar uma crítica às Ciências Sociais, visando superar o caráter linear e não histórico do modelo positivista de ciência. Nessa ordem de raciocínio, tanto uma abordagem quanto a outra busca evocar o passado para a compreensão do sujeito presente, ideologicamente assujeitado, realizando não somente uma releitura da História, mas utilizando-a como uma estratégia temporal que não é linear.

Outra similaridade consiste no fato das duas vertentes reconhecerem que o sujeito não tem condições de escolher estar dentro ou fora da ideologia, sendo interpelado por ela e assujeitado a uma conjuntura que, por mais que pareça óbvio, como lembra Louis Althusser (1974), escapa ao seu controle. Contudo, "o paradigma decolonial luta por fomentar a divulgação de outra interpretação que põe em evidência uma visão silenciada dos acontecimentos e [...] mostra os limites de uma ideologia imperial que se apresenta como a verdadeira e única interpretação" (MIGNOLO, 2007, p. 457).

As discussões pertinentes ao "lugar de fala"4 - termo (de)colonial associado ao protagonismo de fala daquele que vivencia a experiência investigada - também parecem coadunar com os estudos da $\mathrm{AD}$, sobretudo no que concerne à Formação Discursiva $(\mathrm{FD})^{5}$,

4 "Lugar de fala" é um termo utilizado pela perspectiva teórica (de)colonial para fazer referência ao protagonismo de fala daquele(a) que vivencia a experiência investigada, conforme proposto por Djamila Ribeiro (2017).

5 Termo emprestado de Michel Foucault e desenvolvido por Pêcheux, com base nas contribuições do materialismo histórico. Em seu texto, produzido em 1969, Pêcheux discute a noção de Formação Social, considerando que o sujeito fala de distintos lugares sociais, parecendo já apontar para um "lugar" que policia os dizeres dos sujeitos. 
da escola francesa. O conceito está, diretamente, associado ao lugar discursivo de onde os sujeitos enunciam, determinando o que pode ou não ser dito. Chega-se, assim, à chamada posição discursiva, ocupada pelo sujeito que não enuncia somente de um lugar, mas a partir dos diversos discursos que o alcançaram ao longo de sua existência.

$\mathrm{Na}$ interface proposta, portanto, parece ser possível apontar as contradições naturalizadas e proferidas pelo sujeito, denunciando a ideologia que o atravessa, seja em torno de ideia de "raça" ou "classe". Ambas as categorias estão associadas à classificação social da população mundial, distinguindo-se, nas análises, pelos marcos temporais tomados como parâmetro (o Giro Decolonial tem como marco de análise o ano de 1492, data da invasão do continente latino-americano).

Há, contudo, alguns desafios que precisam ser superados para que a $\mathrm{AD}$, pecheutiana, enquanto abordagem metodológica, ofereça contribuições sólidas aos estudos (de)coloniais, em que a linguagem seja tomada como referencial de análise.

O principal limite diz respeito à colonialidade do campo discursivo, que se reproduz nos livros e nas universidades, sendo consideradas de prestígio, no contexto latino-americano, sobretudo as obras de origem europeia ou estadunidense. Como pontua Viviane de Melo Resende (2017), "nascer em inglês ou em francês, para os estudos discursivos, é sair na frente, e publicar textos nos locais de prestígio do campo, nessas línguas, é poder ecoar sua voz" (RESENDE, 2017, p. 3).

Isso resulta em grande esforço de aplicação de teorias, importadas como universalmente válidas, e pouco atualizadas no contexto local. A consequência, para os estudos discursivos latino-americanos, é a dependência cultural. Há pouca confiança, por parte dos pesquisadores da América Latina, na legitimação de ideias próprias, que precisam ser outorgadas por teóricos europeus ou estadunidenses.

Como resultado, tem-se um conjunto de teorias importadas, no campo do discurso, que se propõe a representar a voz e fixar a identidade do subalterno, assumindo o "lugar de fala" que não lhe é próprio. Mas como pensar a AD desde (e para) o Sul? Como superar os limites entre a AD, francesa, e a Teoria (De)colonial, enquanto perspectivas metodológica e teórica? Como dar voz aos pesquisadores silenciados? Como permitir que as culturas "falem", legitimando as epistemes que lhes são pertinentes? O quadro 1 aponta algumas possíveis respostas para os questionamentos formulados. 
Quadro 1: AD, pecheutiana, e Teoria (De)colonial: limites e desafios para um diálogo teórico-metodológico

\begin{tabular}{|c|c|c|}
\hline & Limites & Desafios \\
\hline $\begin{array}{l}\text { Colonialidade } \\
\text { do Poder }\end{array}$ & $\begin{array}{l}\text { - A maior parte da literatura } \\
\text { legitimada, no campo do discurso, } \\
\text { tem origem no Norte. Basta } \\
\text { pensar na influência de autores, } \\
\text { como Michel Pêcheux e Michel } \\
\text { Foucault, nos estudos discursivos } \\
\text { latino-americanos; } \\
\text { - A colonialidade do campo } \\
\text { discursivo está presente nas } \\
\text { estruturas institucionais do Sul, } \\
\text { reproduzindo-se nos livros e nas } \\
\text { Universidades. }\end{array}$ & $\begin{array}{l}\text { - Questionar a legitimidade } \\
\text { de discursos, universais e } \\
\text { territorializados, para o contexto } \\
\text { latino-americano; } \\
\text { - Praticar a "desobediência } \\
\text { epistêmica"6, necessária ao } \\
\text { rompimento das estruturas } \\
\text { tradicionais do saber; } \\
\text { - Incorporar, ao debate, as } \\
\text { condições de produção do } \\
\text { discurso latino-americano, tendo } \\
\text { como marco o ano de } 1492- \\
\text { quando a América Latina foi } \\
\text { invadida pelos povos europeus. }\end{array}$ \\
\hline $\begin{array}{c}\text { Colonialidade } \\
\text { do Saber }\end{array}$ & $\begin{array}{l}\text { - Os sustentáculos das vozes latino- } \\
\text { americanas falam outras línguas; } \\
\text { - É comum, entre o(a)s analistas } \\
\text { de discurso ortodoxos, de linha } \\
\text { francesa, seguir um círculo de } \\
\text { autores legitimados; } \\
\text { - A linguagem costuma ser bastante } \\
\text { especializada, dificultando a } \\
\text { compreensão por leitores de } \\
\text { outros "lugares de fala". }\end{array}$ & $\begin{array}{l}\text { - Reconhecer o que as teorias, } \\
\text { do Norte global, são de fato: } \\
\text { perspectivas territorializadas, } \\
\text { como quaisquer outras, não } \\
\text { superiores, válidas para os } \\
\text { contextos em que foram } \\
\text { produzidas; } \\
\text { - Conscientizar-se de que } \\
\text { todo conhecimento é situado } \\
\text { e que toda teoria deve ser } \\
\text { contextualizada para que tenha } \\
\text { utilidade; } \\
\text { - Reconhecer, humildemente, } \\
\text { as alteridades, o que implica } \\
\text { falar outra língua, acessível } \\
\text { não somente às demais } \\
\text { especialidades, mas, sobretudo, } \\
\text { aos grupos sociais externos à } \\
\text { universidade. }\end{array}$ \\
\hline
\end{tabular}

Termo emprestado de Boaventura de Sousa Santos. 


\begin{tabular}{|c|c|c|}
\hline $\begin{array}{c}\text { Colonialidade } \\
\text { do Ser }\end{array}$ & $\begin{array}{l}\text { - Baixa autoestima, científica, de } \\
\text { parte do(a)s pesquisadore(a) } \\
\text { s, latino-americano(a)s, que se } \\
\text { ocupam dos estudos discursivos; } \\
\text { - Pouca confiança na legitimidade } \\
\text { de ideias próprias, que precisam } \\
\text { ser outorgadas por teóricos do } \\
\text { Norte global. }\end{array}$ & $\begin{array}{l}\text { - Reconhecer que ocupamos } \\
\text { um espaço, academicamente } \\
\text { subalterno, nos estudos do } \\
\text { discurso, sendo necessário reagir } \\
\text { a isso; } \\
\text { - Preservar a autocrítica, o } \\
\text { respeito à criatividade produtiva } \\
\text { do Sul e apreço à diversidade } \\
\text { epistemológica; } \\
\text { - Praticar a "desobediência } \\
\text { epistêmica", assumindo uma } \\
\text { postura ousada, necessária } \\
\text { ao empreendimento de } \\
\text { novas alternativas teórico- } \\
\text { metodológicas. }\end{array}$ \\
\hline
\end{tabular}

Fonte: elaborado pelas autoras com base nas contribuições de Resende (2017).

Pensar a AD desde (e para) o Sul implica, portanto, três grandes desafios: "decolonizar o poder", assumindo a potência de criação teórico-metodológica local; "decolonizar o saber", tecendo críticas às teorias e aos métodos que se propõem universais, e; “decolonizar o ser", buscando alternativas que possibilitem romper com a baixa autoestima do(a)s pesquisadore(a) s latino-americano(a)s, fazendo uso estratégico desse espaço subalternizado, que carrega as potencialidades de novos horizontes teóricos, rumo a uma "ecologia de saberes"7.

Tal atitude, contudo, não deve ser confundida com a rejeição da produção humana do Norte global, conforme expressa Luciana Ballestrin, nem com a necessidade de criação de um marco zero de análise, com foco em temáticas restritas.

(De)colonizar os estudos do discurso, a partir de perspectivas latino-americanas, implica reconhecer que a história, colonial, da América Latina, e seus processos constitutivos de violência, não podem ser ignorados (BALLESTRIN, 2013), sendo imprescindível enfatizar a atualidade do debate, sobre imperialismo, como expressa Emir Sader (2012), dando voz à subalternidade do Sul.

\footnotetext{
"A ecologia de saberes é um conceito que visa promover o diálogo entre vários saberes que podem ser
} considerados úteis para o avanço das lutas sociais pelos que nelas intervêm” (SANTOS, 2014, p. 332). 


\section{Considerações finais}

Com base nas reflexões propostas, depreende-se que é possível pensar a $\mathrm{AD}$, pecheutiana, desde (e para) o Sul, na interface com os Estudos (De)coloniais, como uma abordagem metodológica capaz de contribuir, proficuamente, para a compreensão dos processos de dominação e classificação, universal, dos sujeitos.

Tal combinação - da AD com a Teoria (De)colonial - possibilita vislumbrar um presente ainda permeado por discursos que coadunam na perpetuação da assimetria da distribuição do poder. Permite identificar padrões - racistas, capitalistas e sexistas - que limitam a ação, transformadora, dos sujeitos latino-americanos, reproduzidos consciente ou inconscientemente.

Logo, a interface proposta parece ser rica para ambas as partes: de um lado, os Estudos (De)coloniais podem proporcionar à $\mathrm{AD}$ a potencialização do método que lhe é próprio; de outro, a $\mathrm{AD}$ pode possibilitar maior rigor metodológico às análises discursivas (de)coloniais, auxiliando na identificação e na visibilização das identidades do Sul.

Contudo, faz-se necessário superar os limites desta interface, situados na colonialidade do campo, que impedem que os vários discursos científicos possam coexistir. Isso demanda, das instituições de ensino, o reconhecimento de que a territorialidade faz os pesquisadores sujeitos de seu próprio espaço e tempo, exigindo do(a) analista uma postura de autonomia e de potência de criação teórico-metodológica local, necessária ao estabelecimento de diálogo, horizontalizado, com as teorias do Norte global.

Assumindo seu "lugar de fala", o(a) analista poderá usufruir de todo o rigor metodológico da $\mathrm{AD}$, pecheutiana, atualizando-o para o contexto local. Assim, poderá apontar as contradições naturalizadas e proferidas pelo sujeito latino-americano, denunciando a ideologia que o atravessa, em torno da ideia de "raça-classe-gênero"- categorias que se mantêm fundantes, na América Latina, desde a invasão do continente, pelos povos europeus, em 1492.

\section{Referências}

ALTHUSSER, Louis. Ideologia e aparelhos ideológicos de Estado. Lisboa: Presença/ Martins Fontes, 1974.

BALLESTRIN, Luciana. América Latina e o giro decolonial. Revista Brasileira de Ciência Política, v. 11, p. 89-117, 2013.

BARBOSA, Emanuelle de Souza. Marcas da colonialidade nos discursos de documentos oficiais na política de inserção de tecnologias digitais de informação e comunicação na educação básica. Dissertação (Mestrado em Educação Contemporânea) - Universidade Federal de Pernambuco, Caruaru, 2016.

CARVALHO, Frederico Zeymer Feu de. n: Pêcheux e Lacan. Tese (Doutorado em Linguística) -Universidade Federal de Minas Gerais, Belo Horizonte, 2008.

GUERRA, Luiz Antonio. Pós-colonialismo. InfoEscola: Navegando e Aprendendo, 2014. Disponível em: <https://www.infoescola.com/historia/pos-colonialismo/>. Acesso em: 5 fev. 2020. 
MALDIDIER, Denise. A inquietação do Discurso: (re)ler Michel Pêcheux hoje. Campinas: Pontes, 2003.

MIGNOLO, Walter. Delinking. The rethoric of modernity, the logic of coloniality and the grammar of de-coloniality. Cultural studies, n. 21, v. 2-3, 2007.

La idea de América Latina. La herida colonial y la opción decolonial. Barcelona: Gedisa, 2005.

PÊCHEUX, Michel. O discurso: estrutura ou acontecimento. 5. ed. Campinas: Pontes, 2008.

Análise de Discurso. 4. ed. Campinas: Pontes, 2014a.

Semântica e Discurso. 5.ed. Campinas: Unicamp, 2014b.

PORTO-GONÇALVES, Carlos Walter. Apresentação da edição em português. In: LANDER, Edgardo (org). A colonialidade do saber: eurocentrismo e ciências sociais. Buenos Aires: CLASCO, 2005, p. 1-4.

QUIJANO, Aníbal. Cuestiones y horizontes: de la dependencia histórico-estructural a la colonialidad/descolonialidad del poder. Buenos Aires: CLACSO, 2014.

Colonialidade do poder e classificação social. In: SANTOS, Boaventura; MENEZES, Maria Paula (Orgs.). Epistemologias do Sul. São Paulo: Almedina, 2009, pp. 105-115.

RESENDE, Viviane de Melo. Decolonizar os estudos críticos do discurso: por perspectivas latino-americanas. Conferência. In: XII Congresso Internacional da ALED, Santiago do Chile, 18 de outubro de 2017, p. 3.

RIBEIRO, Djamila. O que é lugar de fala?. Belo Horizonte: Letramento, 2017.

SADER, Emir. Pós-neoliberalismo na América Latina. In: MARTINS, Paulo Henrique; RODRIGUES, Cibele (Orgs.) Fronteiras abertas da América Latina: Diálogo na ALAS. Recife: Editora da UFPE, 2012.

SANTOS, Boaventura de Sousa. A Praxis da Ecologia de Saberes: entrevista de Boaventura de Sousa Santos. Tempus, actas de saúde coletiva, v. 8, n. 2, p. 331-338, jun, 2014. 